\title{
"MANTO DA MASSA": PERTENCIMENTO, COCRIAÇÃO E ENGAJAMENTO EM UMA CAMPANHA HISTÓRICA DE VENDAS DE CAMISAS OFICIAIS NO FUTEBOL BRASILEIRO
}

\author{
iD Christian Gomes e Souza Munaier \\ Mestre em Administração pela Pontifícia Universidade Católica de São Paulo (PUC-SP) \\ Doutorando pelo Programa de Pós-graduação em Administração da Faculdade de Economia, \\ Administração, Contabilidade e Atuária da Universidade de São Paulo (FEA - USP) \\ munaier@usp.br
}

\section{Resumo}

Objetivo do estudo: o presente estudo buscou analisar o engajamento, o sentimento de pertencimento ao grupo, a cocriação de valor e a renda na campanha "O Manto da Massa", que gerou a venda de 100.000 camisas em 8 dias pelo Clube Atlético Mineiro, campanha de comercialização histórica no cenário da gestão do esporte brasileiro.

Metodologia/abordagem: 555 questionários respondidos e validados foram tratados em uma metodologia quantitativa multivariada (Modelagem de Equações Estruturais e ANOVA).

Originalidade/Relevância: este artigo contribui para o avanço da literatura sobre o ecossistema de serviços, no marketing esportivo, baseado nas experiências do consumidor na cocriação de valor. Para tanto, analisou a importância do pertencimento ao grupo e a cocriação de valor no engajamento de torcedores dos clubes de futebol nos resultados comerciais das campanhas de lançamento de uniformes, estudando a mais bemsucedida campanha de comercialização de uniformes de um clube de futebol brasileiro.

Principais resultados: dentre os achados, destaca-se que quanto maior a sensação de pertencimento do indivíduo, maior o engajamento e o desejo de participar dos processos de cocriação do uniforme com o fornecedor. E que o engajamento via cocriação é maior do que o engajamento apenas pelo pertencimento. Também é possível sustentar que quando há engajamento na divulgação feita pelo comprador para que outros também consumam, maior o seu próprio volume de compra, além de observar que o apreço à promoção diminui conforme aumenta a renda do comprador.

Contribuições teóricas/metodológicas: o presente manuscrito avança no entendimento sobre a importância do pertencimento e da cocriação de valor no comportamento do consumidor e as campanhas de clubes de futebol, e propõe que o engajamento em mídias sociais seja uma variável mediadora entre o pertencimento, a cocriação e o volume de compra feito pelo consumidor. Registra-se também importante contribuição nos estudos sobre o apreço à promoção.

Contribuiç̃̃es sociais / para a gestão: este artigo avança na análise de comportamentos que impactaram na campanha histórica de comercialização de uniformes cocriados por torcedores de um clube de futebol, iluminando estratégias de gestão para clubes que almejarem resultados semelhantes aos obtidos pelo Clube Atlético Mineiro na campanha "O Manto da Massa".

Palavras-chave: Grupo de referência. Cocriação de valor. Apreço à promoção. Engajamento. gestão do futebol.

\section{Cite como}

American Psychological Association (APA)

Munaier, C. G. e S. (2021, set./dez.). "Manto da massa": pertencimento, cocriação e engajamento em uma campanha histórica de vendas de camisas oficiais no futebol brasileiro. PODIUM Sport, Leisure and Tourism Review, São Paulo, 10(4), 81-108. https://doi.org/10.5585/podium.v10i4.18962. 
Munaier, C. G. e S. (2021, set./dez.). "Manto da massa": pertencimento, cocriação e engajamento em uma campanha histórica de vendas de camisas oficiais no futebol brasileiro

\section{"MANTO DA MASSA": BELONGING, CO-CREATING, AND ENGAGING IN A HISTORICAL CAMPAIGN OF OFFICIAL SHIRT SALES IN BRAZILIAN FOOTBALL (SOCCER)}

\section{Abstract}

The objective of the study: the present study sought to analyze engagement, the feeling of belonging to the group, the co-creation of value and income in the "O Manto da Massa" campaign, which generated 100,000 shirts sold in 8 days by Clube Atlético Mineiro, a historical campaign of commercialization in the Brazilian sport management scenario.

Methodology/approach: 555 questionnaires answered and validated were treated using a multivariate quantitative methodology (Structural Equation Modeling and ANOVA).

Originality/Relevance: this article contributes to advancing the literature on the ecosystem of services, in sports marketing, based on consumer experiences in value co-creation. To this end, it analyzed the importance of belonging to the group and the value co-creation in the engagement of soccer club fans in the commercial results of the uniform launch campaigns, studying the most successful uniform marketing campaign of a Brazilian soccer club.

Main results: among the findings, it stands out that the greater the individual's sense of belonging, the greater the engagement and the desire to participate in the co-creation processes of the uniform with the supplier. Moreover, that engagement via co-creation is greater than engagement just by belonging. It is also possible to maintain that when there is engagement in the buyer's disclosure so that others also consume, the greater their own volume of purchase, in addition to observing that the appreciation of the promotion decreases as the buyer's income increases.

Theoretical/methodological contributions: the present manuscript advances understanding the importance of belonging and the co-creation of value in consumer behavior and football club campaigns. It proposes that social media engagement be a mediating variable between belonging, co-creation, and the consumer's volume of purchase. There is also an important contribution to studies on the appreciation of promotion.

Social/management contributions: this article advances the analysis of behaviors that impacted the historic marketing campaign for uniforms co-created by fans of a football club, illuminating management strategies for clubs that want results like those obtained by Clube Atlético Mineiro in the campaign "O Manto da Massa".

Keywords: Reference group. Co-creation of value. Appreciation for promotion. Engagement. Football management

\section{"MANTO DA MASSA": PERTENENCIA, CO-CREACIÓN Y ENGAGEMENT EN UNA CAMPAÑA HISTÓRICA DE VENTA DE CAMISETAS OFICIALES EN EL FÚTBOL BRASILEÑO}

\section{Resumen}

Objetivo del estudio: el presente estudio buscó analizar el engagement, el sentimiento de pertenencia al grupo, la cocreación de valor e ingresos en la campaña "O Manto da Massa”, que generó 100.000 camisetas vendidas en 8 días por el Clube Atlético Mineiro, campaña de comercialización histórica en el escenario de la gestión deportiva brasileña.

Metodología/enfoque: Se trataron 555 cuestionarios contestados y validados mediante una metodología cuantitativa multivariante (Modelado de Ecuaciones Estructurales y ANOVA).

Originalidad/Relevancia: este artículo contribuye al avance de la literatura sobre el ecosistema de servicios, en el marketing deportivo, a partir de las experiencias del consumidor en la co-creación de valor. Para este fin, analizó la importancia de la pertenencia al grupo y la co-creación de valor en la implicación de los aficionados (hinchada) de los clubes de fútbol en los resultados comerciales de la campaña de lanzamiento de uniformes, analizando la campaña de marketing más exitosa para uniformes de un club de fútbol brasileño.

Principales resultados: entre los hallazgos, se destaca que cuanto más fuerte es el sentido de pertenencia del individuo, más fuerte el engagement y deseo de participar en los procesos de co-creación del uniforme con el proveedor. Y ese engagement a través de la co-creación es más fuerte que el engagement por pertenecer. También es posible sostener que cuando hay engagement en la divulgación que hace el comprador para que otros también consuman, mayor es el volumen propio de compra, además de observar que la apreciación de la promoción disminuye a medida que aumentan los ingresos del comprador.

Aportes teóricos/metodológicos: el presente manuscrito avanza en la comprensión de la importancia de la pertenencia y la co-creación de valor en el comportamiento del consumidor y las campañas de los clubes de fútbol, y propone que el engagement en las redes sociales es una variable mediadora entre pertenencia, la co-creación y el volumen de compra realizado por el consumidor. También hay una contribución importante a los estudios sobre la valoración de la promoción.

Contribuciones sociales/gerenciales: este artículo avanza en el análisis de comportamientos que impactaron la histórica campaña de marketing de camisetas co-creada por aficionados de un club de fútbol, iluminando estrategias de gestión para clubes que quieren resultados similares a los obtenidos por el Clube Atlético Mineiro en la campaña "O Manto da Massa".

Palabras clave: Grupo de referencia. Co-creación de valor. Aprecio por la promoción. Engagement. Gestión de fútbol. 
Munaier, C. G. e S. (2021, set./dez.). "Manto da massa": pertencimento, cocriação e engajamento em uma campanha histórica de vendas de camisas oficiais no futebol brasileiro

\section{Introdução}

Os produtos licenciados comercializados por clubes de futebol e seus parceiros geram receitas significativas e fortalecem os laços de identidade entre os times e seus e torcedores (Kolyperas et al., 2019; Nalbantis et al., 2017). Em 2014, foi gerado um valor aproximado de US\$ 26 bilhões no mercado global (Nalbantis et al., 2017). Assim, clubes de futebol elaboram estratégias no afã de estimular o ímpeto de compra de seus torcedores, seja pelo valor promocional, seja por meio do apelo emocional do pertencimento por parte do indivíduo (Hewer et al., 2017; Lichtenstein et al., 1993; Park \& Lessig, 1977). Nos últimos anos, clubes e seus parceiros comerciais vêm buscando criar ações para potencializar suas estratégias nas vendas de produtos licenciados (Hewer et al., 2017; Kolyperas et al., 2019; Tsiotsou, 2016). Em 2020, a participação da torcida no processo de escolha - e até mesmo de criação - das peças comercializadas pelos clubes ganhou novo protagonismo: as ações de clubes como Náutico (PE), Ceará (CE), Atlético (MG) e Ponte Preta (SP), que trouxeram seus torcedores ao processo de elaboração das propostas de uniforme e eleição do mais votado para a sua comercialização (GE, 2020a).

Observar o que essas ações trazem de estratégias demonstra-se relevante para o avanço da literatura sobre a cocriação de valor pelos fãs de esporte em sua relação de consumo das marcas (Kolyperas et al., 2019). Em que pese o tema da cocriação de valor no marketing esportivo estar ganhando relevância nos últimos anos (Kolyperas et al., 2019; Tsiotsou, 2016), é ainda uma produção insipiente na pesquisa acadêmica nos consumos esportivos (Kolyperas et al., 2019). Tratando-se de cocriação de valor na elaboração de camisas oficiais do clube e no engajamento do consumidor, não foram identificadas pesquisas até o momento da redação do presente artigo. Assim, este manuscrito propõe analisar, dentro da gestão esportiva de um clube de futebol e de suas ações comerciais, a importância do pertencimento, da cocriação de valor, do engajamento e do apreço à promoção na ação estratégia de trazer seu torcedor para o processo de desenvolvimento e escolha de uma das peças que irá compor o enxoval anual de uniformes do clube. Ainda, visa a analisar em que medida esses elementos impactam positivamente nos resultados das campanhas de comercialização dessas peças.

A ação executada pelo Atlético-MG foi retratada pela imprensa pelo seu resultado financeiro. Durante os dias 12 a 20 de junho de 2020, em meio à pandemia da COVID-19, a campanha atleticana tornou-se a ação promocional de venda de uniforme mais bem-sucedida 
Munaier, C. G. e S. (2021, set./dez.). "Manto da massa": pertencimento, cocriação e engajamento em uma campanha histórica de vendas de camisas oficiais no futebol brasileiro

da história do futebol brasileiro, gerando uma receita superior a R\$ 19 milhões. Como se noticiou na época, o Atlético-MG de fato alcançou um feito histórico (GE, 2020b).

O Clube Atlético Mineiro fez uma campanha chamada "O Manto da Massa", em parceria com a fornecedora francesa de artigos esportivos Le Coq, sua patrocinadora em 2020. O mote central: torcedoras e torcedores enviariam suas propostas de design para uma versão oficial da camisa do Atlético, sendo que a mais votada pela própria torcida seria produzida pela fornecedora e vendida pelo clube. Parte do valor arrecadado seria doado para o combate à pandemia da COVID-19. A campanha foi dividida em três etapas: 1) recebimento dos "mockups" enviados pela torcida; 2) votação no site www.mantodamassa.com.br; 3) anúncio do vencedor e início das vendas através do mesmo site. Segundo o site da promoção, foram 1.500 projetos enviados, 50.000 votos computados, gerando 13 finalistas. A proposta enviada pelo torcedor Flávio Markiewickz foi a escolhida, chegando à marca de 100.000 peças vendidas em 8 dias (CAM, 2020).

\section{Figura 1.}

Imagem Ilustrativa do Manto da Massa em Comemoração à Venda das 100.000 Camisas.

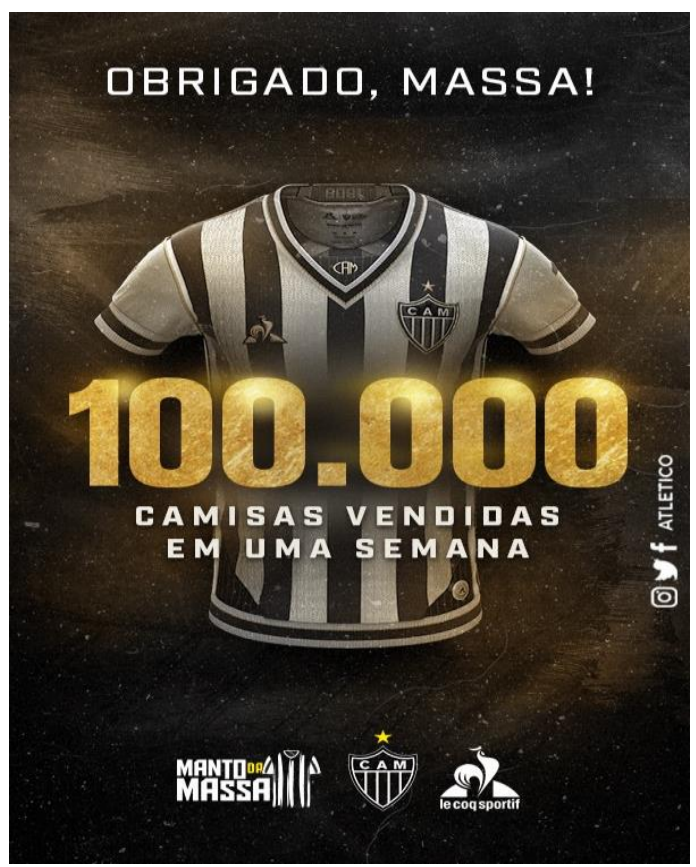

Fonte: CAM (2020). 
Munaier, C. G. e S. (2021, set./dez.). "Manto da massa": pertencimento, cocriação e engajamento em uma campanha histórica de vendas de camisas oficiais no futebol brasileiro

Para além do aspecto emocional que o consumo de camisas de futebol e preços promocionais (como foi o caso na aludida campanha) proporcionam (Hewer et al., 2017), este artigo busca identificar o papel da cocriação de valor por parte do consumidor no processo de desenvolvimento e escolha do objeto do seu consumo. Para tanto, é proposta uma escala adaptada para mensurar a importância da cocriação em ações comerciais em clubes de futebol, sendo essa uma das contribuições deste manuscrito para a literatura. Ainda, busca-se mensurar o quanto o engajamento do indivíduo impactou não apenas na sua escolha de compra, mas no volume de peças adquiridas. Ainda, busca-se avançar nas pesquisas sobre cocriação de valor e engajamento das torcidas (fandoms, em inglês) e o consumo, uma lacuna de conteúdo acadêmico (Hewer et al., 2017; Kolyperas et al., 2019).

Para isso, o manuscrito discorre, em um primeiro momento, sobre a fundamentação teórica sobre Grupo de Referência, Cocriação de Valor, Engajamento nas Mídias Sociais, Renda e Apreço à Promoção, bem como apresenta as hipóteses e modelo teórico a ser testado. $\mathrm{Na}$ sequência, são apresentados os resultados tratados e analisados da escala aplicada, demonstrando que o ecossistema de pertencimento e cocriação potencializam o engajamento do torcedor-consumidor. Por fim, demonstra ainda o papel do engajamento não apenas para a decisão de compra, mas para o volume comprado. Conclusões, limitações, recomendações para novas pesquisas estão na sequência.

\section{Referencial teórico e hipóteses}

Nesta seção, serão apresentados os principais pilares teóricos deste estudo.

\subsection{Pertencimento, cocriação de valor e engajamento}

Manter relações sociais estáveis é fundamental para a sobrevivência e a segurança humana (Maslow, 1970). O desejo do indivíduo é permanecer membro de uma comunidade com a qual seus valores e condutas sejam sinérgicos e lhe proporcionem a sensação de pertencimento (Huang \& Chen, 2018). O consumo é uma atividade humana que tem, em seu cerne, a tomada de decisão do indivíduo na sua definição quanto ao seu 'eu' interior, além de um 'eu' agregado, num processo de autoconstruções através das posses, consideradas por seus proprietários como tendo diferentes graus de centralidade em um ou mais de seus sentidos individuais ou agregados de si (Belk, 2013). Ao final e ao cabo, o indivíduo busca se credenciar ao grupo através de suas posses, que emitem sinais de que ele pode ser parte dessa 'tribo'. Ser 
Munaier, C. G. e S. (2021, set./dez.). "Manto da massa": pertencimento, cocriação e engajamento em uma campanha histórica de vendas de camisas oficiais no futebol brasileiro

rejeitado ou ignorado geralmente sugere dissimilaridade ou desacordo entre os indivíduos excluídos e a entidade social da qual eles são excluídos (Hewer et al., 2017; Wan et al., 2014).

O pertencer ou ser excluído das tribos toma uma dimensão muito maior na era da internet, onde o 'eu' assume avatares com os quais nos identificamos, que podem afetar nosso comportamento offline e nosso senso de identidade (Belk, 2013). A natureza mais compartilhada do 'eu', advinda das relações sociais no âmbito digital, apresenta uma característica de cocriação desse novo 'eu', resultado dos feedbacks instantâneos vindo das postagens (likes e demais reações), que podem ajudar a afirmar ou modificar próprio senso de si (Belk, 2013). Afinal, um indivíduo utiliza grupos de referência para se expressar ou reforçar seu ego, "havendo uma consistência entre o desejo de se expressar e a imagem psicológica anexada ao Grupo de Referência” (Park \& Lessig, 1977).

O pertencimento ao grupo de referência é um forte elemento no comportamento do consumidor, e os clubes de futebol se valem desse sentimento para estimular seu público-alvo ao consumo (Hewer et al., 2017). Em cidades como Belo Horizonte/MG e região metropolitana, o fato de haver dois grandes rivais - Atlético e Cruzeiro -, vestir seu "manto" é também se definir diante do outro. No interior de Minas, é possível identificar torcedores de clubes de suas microrregiões ou, até mesmo, de outros estados. Vestir o uniforme do seu clube é uma questão de defesa de territorialidade, deste conjunto impregnado de significados, símbolos e imagens da autoidentidade (Freyre, 1996; Rosendahl, 2005) e até mesmo de confiança (Munaier et al., 2020; Munaier \& da Costa, 2021). E, fora de Minas, vestir a camisa de futebol pode ser, também, uma manifestação da sua cultura e ancestralidade. Diante desses conceitos, emerge a primeira hipótese.

$\mathrm{H}_{1}$ : A sensação de pertencimento que vestir a camisa de um time traz independe da região de residência do respondente.

O significado do clube para seu torcedor e sua sensação de pertencimento ao que Tsiotsou (2016) chamou de lógicas e rituais tribais, já estão postos antes mesmo da ação comercial de cocriação ser proposta e executada. Ser parte dessa tribo é preponderante para os consumos e responde ao por que indivíduos compram camisas de seus clubes em geral (Nalbantis et al., 2017). Mas a ação executada pelo Atlético-MG ultrapassou os resultados convencionais de suas vendas. Ou seja, o sentimento de pertencimento, por si, não seria suficiente impactar no volume observado de compras por parte do indivíduo na campanha em questão. Afinal, os torcedores do "Galo" eram os mesmos antes da campanha e as vendas, ainda 
Munaier, C. G. e S. (2021, set./dez.). "Manto da massa": pertencimento, cocriação e engajamento em uma campanha histórica de vendas de camisas oficiais no futebol brasileiro

que sempre significativas na receita do clube, não se dão nesse volume em tão curto período ( 8 dias). O que leva o presente estudo a hipotetizar:

$\mathrm{H}_{2}$ : A importância dada ao Grupo de Referência é insuficiente para impactar no volume de compra do indivíduo.

Para Ikeda e Veludo-de-Oliveira (2005), o valor para o consumidor não é definido por um processo linear e cognitivo de operações matemáticas, mas sustentado pela percepção de vantagens entre o que ele recebe (qualidade, benefícios, valia, utilidade) e o que ele abre mão para adquirir (preço, tempo, sacrifícios psicológicos ou sociais). Numa outra vertente, a literatura define o valor na experiência de uso é um processo circular contínuo e interativo de construção de sentido individual e coletivo do consumidor (Helkkula et al., 2012). Neste mesmo caminho, Vargo e Lusch (2008), ao revisarem as Premissas Fundamentais (PF) propostas por eles em sua Lógica Dominante Centrada no Serviço (S-D), sugerem que bens (duráveis e não duráveis) derivam seu valor através do uso - o serviço que prestam e que, neste sentido, sustentam ser o cliente um cocriador de valor no uso do bem em uma ação interacional. $\mathrm{Ou}$ seja, é na interação com o objeto que o cliente aquilata o valor do seu consumo, visto ser esse valor idiossincrático, experimental, contextual e com significado carregado (Hughes \& Vafeas, 2018; Vargo \& Lusch, 2008).

A Lógica S-D é a lente teórica com a qual esse artigo se desenvolve, tendo em vista que, no referido campo teórico, o protagonismo passa a ser do consumidor - aqui, torcedor - e das experiências vivenciadas e transformadas por ele na utilização do produto (Lusch et al., 2007; Lusch \& Vargo, 2006).

Para além do valor cocriado pelo usuário de uma camisa de futebol, e dos significados que vesti-la representa enquanto símbolo de pertencimento (Tsiotsou, 2016), o presente artigo avança no sentido da coparticipação do consumidor na elaboração do objeto do seu consumo, na verdadeira sensação de ser partícipe da elaboração e da escolha daquele produto que é um símbolo de pertencimento. E, levando-se em conta a natureza do fenômeno observado - uma votação aberta voltada para escolher, dentre as camisas produzidas por torcedores de um clube, aquela que seria produzida e comercializada pela instituição esportiva -, busca-se entender o valor que participar do processo decisório teve para o engajamento e consumo do uniforme escolhido.

Os fãs de esporte vivem a transformação nos consumos retratados pela literatura quanto ao papel do consumidor em suas experiências de uso (Prahalad \& Ramaswamy, 2000). Os consumidores-fãs de esporte não são meros observadores e receptores do valor criado pelo 
Munaier, C. G. e S. (2021, set./dez.). "Manto da massa": pertencimento, cocriação e engajamento em uma campanha histórica de vendas de camisas oficiais no futebol brasileiro

fornecedor. Os torcedores desejam o protagonismo de voz, cocriando e coproduzindo suas experiências com o clube a quem devotam afeto (Kolyperas et al., 2019). Desta forma, propõese:

$\mathrm{H}_{3}$ : $\mathrm{O}$ pertencimento ao grupo de referência impacta positivamente a importância à cocriação.

O ambiente online pode ser bastante adequado para oferecer suporte a diferentes oportunidades para que o cliente participe de inovações e criação de valor na interação com o fornecedor (Huertas et al., 2012; Nambisan \& Nambisan, 2008). O engajamento dos consumidores de uma marca em sua jornada de cocriação de valor no ambiente online, em comunidade, tem uma natureza complexa e multifacetada, onde a intensidade muda de tempos em tempos (Brodie et al., 2013). O que pesquisadores têm consolidado, como ponto pacífico, é que quanto maior o engajamento na cocriação de valor, maior a lealdade do consumidor a uma marca (Huang \& Chen, 2018; Kandampully et al., 2015). Dentre as funções que podem caber ao cliente no processo de cocriação, estão as de conceitualizador de produtos, designer de produtos, testador de produtos, especialista em suporte a produtos e comerciante de produtos (Nambisan \& Nambisan, 2008). Como sustentam Huertas et al. (2012), que cunharam a expressão "ferramentas de cocriação na internet", lidar com os Ambientes Virtuais do Consumidor (AVC) - desde simples fóruns de discussão online ao processo de desenvolver protótipos de produtos, como se deu na campanha ora em análise - será o desafio para os gerentes. Assim, é proposto:

$\mathrm{H}_{4}$ : O pertencimento ao grupo de referência impacta o engajamento.

Importante notar: é uma meta recorrente do clube vender o máximo de peças licenciadas possível. Por que, nas ações convencionais, o clube eventualmente não alcança um resultado de vendas do mesmo tamanho daquele observado na campanha em análise? Será o engajamento um mediador do resultado de vendas do clube?

An et al. (2019) sustentam que há poucos estudos sobre as motivações sociais e o "boca a boca eletrônico" (eletronic word of mouth - eWOM, em inglês) feito pelos consumidores nas mídias sociais. Neste sentido, An et al. (2019) avançaram no entendimento de que a motivação pró-social leva à participação do cliente, que leva ao compromisso com a marca, resultando no eWOM. Na outra ponta, Munaier e Las Casas (2019) demonstraram que a negligência dos mantenedores dos programas "sócio torcedor" dos clubes ante as reclamações produzidas em sites especializados em coleta de experiências malsucedidas reduz o desejo de novos consumos por parte do seu torcedor. 
Munaier, C. G. e S. (2021, set./dez.). "Manto da massa": pertencimento, cocriação e engajamento em uma campanha histórica de vendas de camisas oficiais no futebol brasileiro

Avançando neste tema, o presente artigo se propõe a avaliar que, não apenas a sensação de pertencimento, mas também a de coparticipar das ações do clube, desde a proposta de uniforme, a escolha e o engajamento na ação explicam o volume de compra recorde observado nesta campanha. Assim, a próxima hipótese é proposta:

$\mathrm{H}_{5}$ : A importância à cocriação impacta mais positivamente o engajamento do que o grupo de referência ao engajamento.

O eWOM e o impacto dos conteúdos gerados por usuários (user-generated content UGC, em inglês) têm sido observados no campo de marketing como ferramentas de engajamento de consumidores e engajamento em ações de promoção e consumo (Lamberton \& Stephen, 2016). Desde que a massificação da internet se tornou uma realidade e expandiu seu papel de fórum de expressão online e como repositório de informações valiosas de ponto a ponto ou de origem social sobre produtos, serviços e marcas, o UGC, geralmente na forma de análises online, tornou-se cada vez mais comum o papel do consumidor como curador de conteúdo (Goldenberg et al., 2012; Lamberton \& Stephen, 2016). Já o eWOM é apontado como importante chave para aumentar a conscientização, atrair tráfego e transformar navegadores em compradores, sendo o envolvimento dos negócios na comunicação online proativa, elementochave no aprimoramento do envolvimento dos consumidores nas atividades eWOM (Standing et al., 2016; M. Zhang et al., 2011).

Assim, o papel do engajamento nas mídias sociais e o consumo estão alicerçados no eWOM e no UCG, sendo possível inferir sobre as novas aquisições de clientes como uma consequência de marketing do eWOM (Trusov et al., 2009; Zhang et al., 2017). Como concluem Zhang et al. (2017), há uma variação significativa na correlação entre o engajamento da rede social e as atividades de compras (nesse caso, a decisão de compra).

O presente artigo busca não apenas observar a importância do engajamento nas mídias sociais para a decisão de compra, visto ser objeto da pesquisa a opinião apenas dos consumidores que já compraram a camisa, mas a relação entre o grau de engajamento e o volume de peças adquiridas. Assim, é proposto:

$\mathrm{H}_{6}$ : O engajamento do comprador impacta positivamente no volume da sua compra.

\subsection{Renda e apreço à promoção}

Renda e apreço à promoção são elementos importantes para entender o comportamento do consumidor. A renda é um critério essencial no consumo e determina tanto o percentual 
Munaier, C. G. e S. (2021, set./dez.). "Manto da massa": pertencimento, cocriação e engajamento em uma campanha histórica de vendas de camisas oficiais no futebol brasileiro

quanto o valor absoluto que cada indivíduo dos diversos estratos socioeconômicos irá destinar para as categorias de bem essencial (alimentação no domicílio), educação, "bens supérfluos" (serviços pessoais e profissionais, como manicure, cabeleireiro, advogado etc.). "Não obstante, mesmo para bens essenciais, a estratificação permite evidenciar diferenças significativas na quantidade consumida e na qualidade dos bens e marcas adquiridos" (Kamakura \& Mazzon, 2016).

Apreço (ou propensão) à promoção é definida por Lichtenstein et al. (1993, p.235) como "uma maior propensão a responder a uma oferta de compra porque a forma de venda na qual o preço é apresentado afeta positivamente as avaliações de compra". A campanha "Manto da Massa" apresentou-se da seguinte forma: as primeiras 92 horas de venda foram exclusivas para sócios Galo na Veia (GNV), com o preço promocional de R \$169,99. Depois dessas 92 horas, os sócios pagariam $\mathrm{R} \$ 225,99$. O preço para quem não fosse GNV seria $\mathrm{R} \$ 269,99$. Com base na literatura aqui apontada, são propostas as seguintes hipóteses:

H7: A condição de sócio do programa Galo na Veia impacta positivamente no volume de compra.

A renda é um elemento importante a definir os consumos. Logo:

$\mathrm{H}_{8}$ : Quanto maior a renda, maior o volume de compra.

Como a renda é um ator importante no consumo (Kamakura \& Mazzon, 2016), é possível inferir que, quanto menor a renda, maior a propensão a responder positivamente a uma oferta de compra na qual o preço é apresentado de forma promocional, estimulando a percepção de oportunidade de compra (Lichtenstein et al., 1993). Assim, é proposto:

$\mathrm{H}_{9}$ : Quanto menor a renda, maior a percepção de oportunidade que a promoção traz.

A Figura 2 apresenta o modelo teórico desenvolvido neste artigo e que contempla as 9 hipóteses testadas. 
Munaier, C. G. e S. (2021, set./dez.). "Manto da massa": pertencimento, cocriação e engajamento em uma campanha histórica de vendas de camisas oficiais no futebol brasileiro

\section{Figura 2.}

Modelo Teórico.

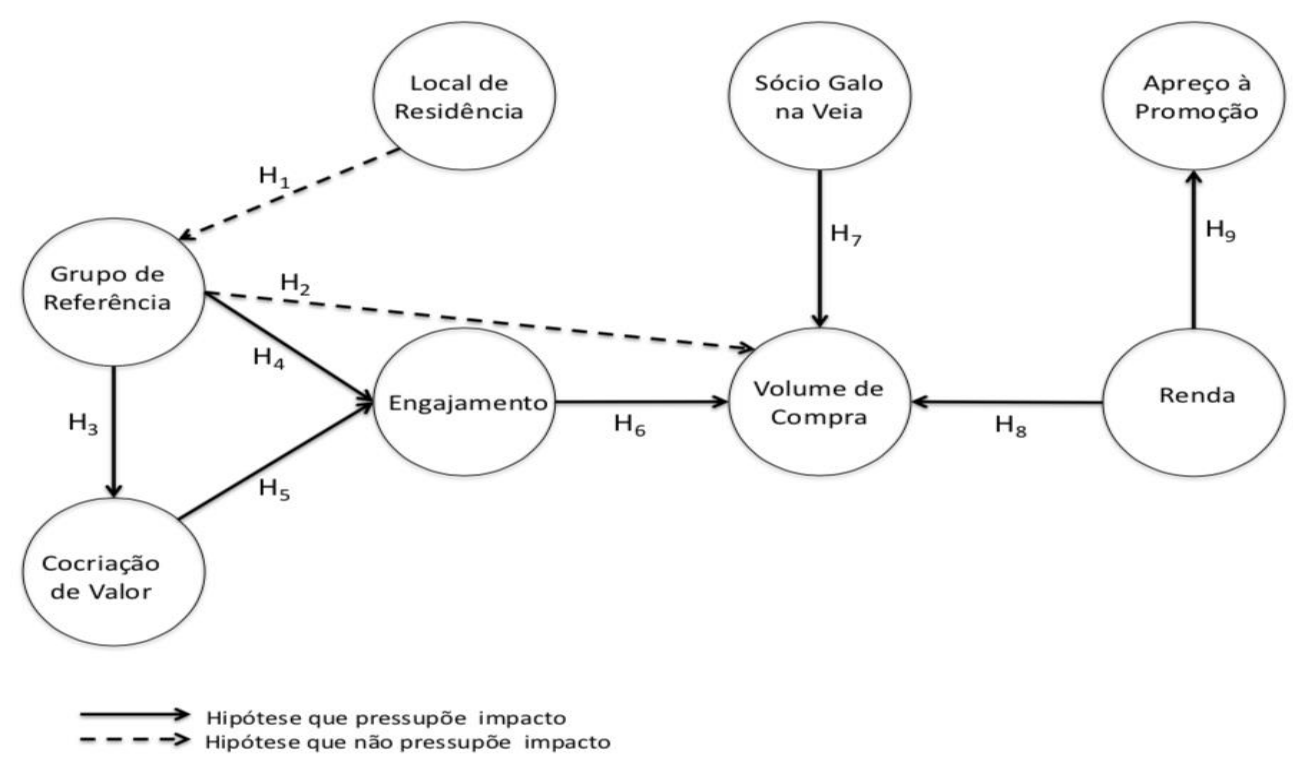

Fonte: Elaborada pelo autor

\section{Método}

A pesquisa realizada é de natureza quantitativa (survey), tendo como propósito entender tendências, atitudes e opiniões de uma amostra (Creswell, 2007).

\subsection{Escala}

Este artigo partiu de escalas validadas, as quais foram traduzidas e analisadas por especialistas em pesquisa de marketing. A escala sobre a importância do uniforme para o grupo de referência foi extraída de Strizhakova et al. (2008). Para testar o apreço à promoção, foi utilizada a escala proposta por Lichtenstein et al. (1993) A exceção se dá pelas variáveis propostas neste artigo para o valor percebido pelo consumidor à cocriação das ações. Essas foram elaboradas a partir da literatura que sustenta o artigo (Huertas et al., 2012; Nambisan \& Nambisan, 2008; Vargo \& Lusch, 2008). Foi aplicado um pré-teste com 15 respondentes. Os ajustes foram feitos a partir das observações propostas por dois especialistas em pesquisa de opinião, ambos professores de Marketing de instituições brasileiras de renome, sendo os ajustes executados na redação dos itens CV1, CV2, CV3 e CV6, para que suas afirmativas fizessem 
Munaier, C. G. e S. (2021, set./dez.). "Manto da massa": pertencimento, cocriação e engajamento em uma campanha histórica de vendas de camisas oficiais no futebol brasileiro

mais sentido aos respondentes. Foi utilizada uma escala tipo Likert de 10 pontos, onde 1 era "discordo totalmente" e 10 "concordo totalmente" às afirmações do questionário.

\subsection{Coleta da amostra}

A coleta das respostas se deu de forma online via link direto para o questionário hospedado na plataforma Google Docs., por meio de postagem nas mídias sociais no mesmo dia em que o clube anunciava a meta alcançada (20 de junho de 2020), sendo o efeito "bola de neve" desejado. Como sustentam Hair et al. (2018), as plataformas online proporcionaram acesso conveniente para amostras de empresas e de consumidores. A ordem da apresentação das variáveis seguia aleatorizada a cada respondente. A coleta durou 48 horas.

\subsection{Seleção da amostra}

Selecionou-se respondentes que atenderam a duas questões-filtro e que foram determinantes para sua sequência ou não ao survey proposto: 1) "É torcedor(a) do Clube Atlético Mineiro?" O respondente que marcasse "não" no questionário não prosseguia para a próxima sessão, sendo excluído. 2) "Você comprou uma ou mais camisas da campanha 'O Manto da Massa'?" Apenas os respondentes que marcassem "sim" no formulário seguiam adiante. Foram preenchidos 586 questionários, dos quais 559 passaram pelos filtros. Verificouse a presença dos outliers, executando o cálculo da distância de Mahalanobis, e foram identificados 4 resultados extremos, sendo extraídos da base. Os resultados dos 555 questionários validados poderão ser observados no capítulo a seguir.

\subsection{Procedimento de análise de dados}

Foram realizadas, incialmente, a análise descritiva dos dados, a análise fatorial exploratória (AFE) e análise fatorial confirmatória (AFC) dos itens das escalas (Hair Jr. et al., 2009). A AFE foi realizada pelo método dos componentes principais com rotação Varimax. Também, foi executada a Modelagem de Equações Estruturais. Com suporte dos softwares IBM SPSS22 e SmartPLS 2.0, foram realizadas todas as análises dos dados. Buscou-se averiguar o alfa de Cronbach $(\alpha \geq 0,7)$, a variância média extraída $(\mathrm{AVE} \geq 0,5)$ e a confiabilidade composta $(\mathrm{CC} \geq 0,7)$ como sendo as premissas mínimas para sua aceitabilidade. Também, avaliou-se o 
Munaier, C. G. e S. (2021, set./dez.). "Manto da massa": pertencimento, cocriação e engajamento em uma campanha histórica de vendas de camisas oficiais no futebol brasileiro

comportamento dos itens de cada construto através do teste de esfericidade de Bartlett $(\mathrm{p}<0,001)$ e o teste de Kaiser-Meyer-Olkin (KMO).

\section{Resultados}

Os questionários voltaram com uma distribuição díspar entre os gêneros: apenas $11 \%$ de respondentes do sexo feminino (61) em detrimento dos $89 \%$ (494) do sexo masculino. O local de residência se apresenta como elemento a ser observado nesta pesquisa. A maioria dos participantes vive no estado de Minas Gerais $(85,4 \%)$, sendo que, em Belo Horizonte e Região Metropolitana, foram $356(64,1 \%)$ e, do interior do estado, 118 (21,3\%). Os outros 14,6\% residem foram de Minas Gerais. Quanto à idade, uma maior concentração entre compradores de 25 a 59 anos. Foram 79 (14,2\%) entre 18 e 24 anos; 306 (55,1\%) entre 25 e 39 anos; 163 $(29,4 \%)$ entre 40 e 59 anos; e apenas $7(1,3 \%)$ de respondentes com 60 anos ou mais. O predomínio de respondentes com ensino superior completo é observado: 13 (2,3\%) com ensino fundamental completo, $151(27,2 \%)$ com ensino médio completo e 391 (70,5\%) com ensino superior completo. A renda, com importância destacada nas hipóteses contidas neste artigo, apresenta-se da seguinte forma entre os respondentes: 7\% (3) sem renda a 1/2 salário-mínimo; 14,8\% (82) de 1 a menos de 2 salários-mínimos; 14,4\% (80) de 2 a menos de 3 saláriosmínimos; 22,2\% (123) de 3 a menos de 5 salários-mínimos; e 41,6\% (231) com 5 saláriosmínimos ou mais.

Dos 555 respondentes validados, 427 (76,9\%) são partícipes do programa de sócio torcedor Galo na Veia. Os outros 128 (23,1\%) compradores, não. Contudo, como registrado na pergunta-filtro de número 1, todos se autodeclararam torcedores do Clube Atlético Mineiro. Do total de respondentes, $463(83,4 \%)$ disseram ter votado na campanha “O Manto da Massa” para eleger o uniforme a ser produzido. $92(16,6 \%)$ não votaram.

Esse engajamento do torcedor pode também ser percebido posteriormente na divulgação e convencimento de outros torcedores a também comprar - e, assim, atingir a meta de 100.000 camisas vendidas. 24,9\% (138) dos respondentes assinalaram não ter participado de qualquer processo de engajamento à campanha. 49,7\% (276) assinalaram uma ação de engajamento (ou redes sociais ou grupos de WhatsApp ou incentivo a familiares e amigos). E $141(25,4 \%)$ disseram ter usadas todas as ferramentas de engajamento. Os meios pelos quais os respondentes buscaram convencer outras pessoas a também aderir à compra do "Manto da Massa" são mais bem observados na Tabela 1 . 
Munaier, C. G. e S. (2021, set./dez.). "Manto da massa": pertencimento, cocriação e engajamento em uma campanha histórica de vendas de camisas oficiais no futebol brasileiro

\section{Tabela 1.}

Distribuição das Ferramentas de Engajamento

\begin{tabular}{lcc}
\hline & $\boldsymbol{n}$ & $\boldsymbol{\%}$ \\
\hline \hline Nenhum & 138 & $24,9 \%$ \\
Redes Sociais & 122 & $22 \%$ \\
WhatsApp & 52 & $9,4 \%$ \\
Incentivo a familiares e amigos & 102 & $18,4 \%$ \\
& & \\
Todos os recursos & 141 & $25,4 \%$ \\
\hline \multicolumn{1}{c}{ Total } & $\mathbf{5 5 5}$ & $\mathbf{1 0 0 \%}$ \\
\hline
\end{tabular}

Fonte: Elaborada pelo autor com dados advindos da coleta

Quanto ao volume de compras do uniforme da campanha "O Manto da Massa", por respondente, deu-se da seguinte forma: 40,5\% (225) compraram 1 peça/cada. 21,6\% (120) compraram 2 peças/cada. E 37,8\% (210) compraram, cada, 3 peças ou mais do uniforme.

As médias, desvios-padrão, análise de multicolinearidade, cargas externas e estatísticas $\mathrm{T}$ advindas dos 555 respondentes podem ser vistas na Tabela 2, bem como as análises de validade dos construtos Grupo de Referência, Apreço à Promoção e Cocriação de Valor. Os softwares "SPSS" e "Smart PLS" foram utilizados para extrair os dados, que serão em seguida analisados. 
Munaier, C. G. e S. (2021, set./dez.). "Manto da massa": pertencimento, cocriação e engajamento em uma campanha histórica de vendas de camisas oficiais no futebol brasileiro

\section{Tabela 2.}

Análises Estatísticas

\begin{tabular}{|c|c|c|c|c|c|c|c|}
\hline Construto & Indicadores & $N$ & Mean & $S D$ & $V I F$ & $\begin{array}{c}\text { Outer } \\
\text { Loadings }\end{array}$ & $\begin{array}{l}\text { Outer Model } \\
\text { T-Statistic }\end{array}$ \\
\hline \multirow{6}{*}{$\begin{array}{l}\text { Grupo de } \\
\text { Referência } \\
\alpha=0,81 \\
\mathrm{AVE}=0,57 \\
\mathrm{CC}=0,87\end{array}$} & $\begin{array}{l}\text { GR1. O uso de roupas do Clube Atlético } \\
\text { Mineiro pode me ajudar a me conectar com } \\
\text { outras pessoas e grupos sociais. }\end{array}$ & 555 & 6,04 & 3,16 & 1,65 & 0,75 & 18,67 \\
\hline & $\begin{array}{l}\text { GR2. Eu compro roupas do Clube Atlético } \\
\text { Mineiro para poder me associar a pessoas e } \\
\text { grupos específicos. }\end{array}$ & 555 & 4,02 & 2,95 & 1,66 & 0,76 & 19,66 \\
\hline & GR3. Sinto um vínculo com pessoas que & 555 & 743 & 270 & 151 & 077 & 1594 \\
\hline & Mineiro que eu. & JJJ & $1,+J$ & 2,10 & $1,{ }_{1}$ & 0,12 & 15,94 \\
\hline & $\begin{array}{l}\text { GR4. Ao escolher um uniforme de futebol, } \\
\text { escolho com quem quero me relacionar. }\end{array}$ & 555 & 4,50 & 3,16 & 1,81 & 0,75 & 16,66 \\
\hline & $\begin{array}{l}\text { GR5. Minha escolha de uniforme de } \\
\text { futebol diz algo sobre as pessoas com que } \\
\text { eu gosto de me relacionar. }\end{array}$ & 555 & 5,12 & 3,21 & 1,92 & 0,80 & 23,36 \\
\hline \multirow{6}{*}{$\begin{array}{l}\text { Apreço à } \\
\text { Promoção } \\
\alpha=0,75 \\
\mathrm{AVE}=0,57 \\
\mathrm{CC}=0,84\end{array}$} & $\begin{array}{l}\text { PR1. Se um produto do Clube Atlético } \\
\text { Mineiro estiver em promoção, isso pode ser } \\
\text { uma razão para eu comprá-lo. }\end{array}$ & 555 & 8,36 & 2,19 & 1,55 & 0,71 & 6,81 \\
\hline & $\begin{array}{l}\text { PR2. Quando compro um uniforme do } \\
\text { Clube Atlético Mineiro que está em } \\
\text { promoção, sinto que estou conseguindo um } \\
\text { bom negócio. }\end{array}$ & 555 & 8,66 & 1,86 & 1,50 & 0,64 & 4,74 \\
\hline & $\begin{array}{l}\text { PR3. Tenho meus uniformes do Clube } \\
\text { Atlético Mineiro desejados, mas na maioria } \\
\text { das vezes compro quando estão em } \\
\text { promoção. }\end{array}$ & 555 & 7,14 & 2,88 & 1,59 & 0,80 & 8,43 \\
\hline & $\begin{array}{l}\text { PR4. Estou mais propenso a comprar os } \\
\text { uniformes do Clube Atlético Mineiro que } \\
\text { estão em promoção. }\end{array}$ & 555 & 8,17 & 2,42 & 1,71 & 0,85 & 12,02 \\
\hline & $\begin{array}{l}\text { CV1. Considero importante o clube } \\
\text { permitir que sua torcida contribua na } \\
\text { elaboração dos seus uniformes. }\end{array}$ & 555 & 9,67 & 0,85 & 1,49 & 0,71 & 10,76 \\
\hline & $\begin{array}{l}\text { CV2. O fato de o clube abrir a votação para } \\
\text { eleger o 'Manto da Massa' é uma forma de } \\
\text { ouvir sua torcida. }\end{array}$ & 555 & 9,64 & 0,92 & 1,39 & 0,67 & 8,26 \\
\hline \multirow{3}{*}{$\begin{array}{l}\text { Cocriarão } \\
\text { de valor } \\
\alpha=0,70 \\
\mathrm{AVE}=0,52 \\
\mathrm{CC}=0,81\end{array}$} & $\begin{array}{l}\text { CV3. Saber que foi um torcedor como eu } \\
\text { quem elaborou o 'Manto da Massa' me } \\
\text { deixa com mais vontade de comprar este } \\
\text { uniforme. }\end{array}$ & 555 & 8,48 & 2,20 & 1,32 & 0,72 & 12,20 \\
\hline & $\begin{array}{l}\text { CV6. Participar das decisões sobre os } \\
\text { produtos que o clube vende é importante } \\
\text { para mim. }\end{array}$ & 555 & 8,77 & 1,90 & 1,53 & 0,78 & 17,47 \\
\hline & Valid N (listwise) & 555 & & & & & \\
\hline
\end{tabular}

Este artigo buscou observar os construtos Grupo de Referência e importância do consumidor à Cocriação de Valor no engajamento e volume de compra na promoção "O Manto da Massa", bem como renda e apreço à promoção. É possível observar, na Tabela 2, as variáveis 
Munaier, C. G. e S. (2021, set./dez.). "Manto da massa": pertencimento, cocriação e engajamento em uma campanha histórica de vendas de camisas oficiais no futebol brasileiro

utilizadas que melhor compuseram cada construto, quanto à sua validade interna e cargas externas. Em todos os quatro construtos, as análises de confiabilidade são validadas e as variáveis se apresentam desprovidas de multicolinearidade. Suas cargas externas e a estatística T de cada indicador também confirmam a qualidade da escala. Para melhor observar a correlação entre os construtos da escala, foi executada uma análise de correlações de bivariáveis no software SPSS 22. Todos os construtos tiveram uma correlação de Pearson $\leq 0,36$, o que significa uma correlação fraca ou desprezível entre os construtos, para melhor validade discriminante.

Nesse sentido, a Tabela 3 mostra a validade discriminante da escala proposta através da matriz de correlação entre os construtos do modelo testado. Utilizou-se o critério de Fornell e Larcker (1981). Conforme preconizado por Hair Jr. et al. (2009, p. 635), "validade discriminante é sustentada quando a variância média extraída para um construto é maior do que a variância compartilhada entre construtos". A tabela 3 demonstra que a escala atende às premissas propostas.

Tabela 3.

Matriz de Correlação Entre os Construtos do Modelo Testado

\begin{tabular}{lccccccccc}
\hline \multicolumn{1}{c}{ Construto } & AVE & Raiz da AVE & $\mathbf{1}$ & $\mathbf{2}$ & $\mathbf{3}$ & $\mathbf{4}$ & $\mathbf{5}$ & $\mathbf{6}$ & $\mathbf{7}$ \\
\hline \hline (1) COCRIAÇÃO & 0,521 & 0,722 & 0,722 & & & & & & \\
(2) COMPRA & 1,000 & 1,000 & 0,031 & 1,000 & & & & & \\
(3) ENGAJAMENTO & 1,000 & 1,000 & 0,292 & 0,155 & 1,000 & & & & \\
(4) GNV STATUS & 1,000 & 1,000 & 0,064 & 0,355 & 0,058 & 1,000 & & & \\
(5) GRUPO & 0,574 & 0,758 & 0,331 & 0,032 & 0,235 & 0,069 & 0,758 & & \\
(6) PROMOÇÃO & 0,571 & 0,756 & 0,241 & $-0,080$ & 0,090 & $-0,022$ & 0,282 & 0,756 \\
(7) RENDA & 1,000 & 1,000 & $-0,047$ & 0,236 & $-0,057$ & 0,182 & $-0,053$ & $-0,189$ & 1,000 \\
\hline
\end{tabular}

Nota. A diagonal em destaque apresenta a raiz quadrada da AVE do construto.

Fonte: Elaborada pelo autor.

Foi executada uma Análise Fatorial Exploratória para cada construto. As 5 variáveis para Grupo de Referência tiveram extração próxima ou superior a 0,5, com $\mathrm{KMO}_{\mathrm{GR}}=0,834$ e $57,6 \%$ de toda a variância explicada num único componente principal, gerando uma variável nomeada de GRUPO R. Para o construto Apreço à Promoção, suas 4 variáveis retornaram com extração próxima ou superior a 0,5 , com $\mathrm{KMO}_{\mathrm{AP}}=0,749$ e $57,6 \%$ de toda a variância explicada num componente principal único, e o resultado de sua regressão sendo nomeada de PROMOÇÃO. Por fim, no construto que analisa a importância dada pelo consumidor à 
Munaier, C. G. e S. (2021, set./dez.). "Manto da massa": pertencimento, cocriação e engajamento em uma campanha histórica de vendas de camisas oficiais no futebol brasileiro

Cocriação de Valor, as 4 variáveis que ficaram tiveram extração próxima ou superior a 0,5, com $\mathrm{KMO}_{\mathrm{CV}}=0,742$ e 52,9\% de toda a variância explicada num componente principal único, e a variável criada a partir de sua regressão sendo nomeada de COCRIAÇÃO.

Com mais de 20 graus de liberdade entre os grupos de faixa de renda, procedeu-se uma ANOVA buscando identificar diferenças entre a importância dada ao Grupo de Referência e a região onde reside o comprador, sendo elas BH e Região Metropolitana $(64,1 \%$ dos respondentes), interior de Minas Gerais $(21,3 \%)$ e outras regiões que não as de atuação principal do Clube Atlético Mineiro (14,6\%). A análise retornou com um $\mathrm{F}(2,552)=0,120 ; \mathrm{p}=0,887$, demonstrando não haver diferença estatisticamente significante entre a média da importância dada ao Grupo de Referência e o local onde reside o comprador. H1, portanto, validada.

A Tabela 4 apresenta os testes das demais hipóteses, na qual os caminhos estruturais contendo a carga original, a carga média, erro padronizado e teste T validaram as 8 hipóteses restantes.

\section{Tabela 4.}

Teste das Hipóteses

\begin{tabular}{|c|c|c|c|c|c|c|}
\hline Caminho estrutural (hipóteses) & Hipótese & $\begin{array}{c}\text { Carga } \\
\text { original }\end{array}$ & $\begin{array}{l}\text { Carga média com } \\
556 \text { repetições em } \\
\text { bootstrap }\end{array}$ & $\begin{array}{c}\text { Erro } \\
\text { padronizado }\end{array}$ & Teste $t$ & $\begin{array}{c}p- \\
\text { value }\end{array}$ \\
\hline GRUPO -> COMPRA & H2 & 0,019 & 0,018 & 0,048 & 0,385 & n.s. \\
\hline GRUPO -> COCRIAÇÃO & H3 & 0,331 & 0,332 & 0,034 & 9,594 & $<.001$ \\
\hline GRUPO -> ENGAJAMENTO & H4 & 0,235 & 0,237 & 0,039 & 5,978 & $<.001$ \\
\hline COCRIAÇÃO -> ENGAJAMENTO & H5 & 0,240 & 0,242 & 0,038 & 6,284 & $<.001$ \\
\hline ENGAJAMENTO -> COMPRA & H6 & 0,151 & 0,149 & 0,038 & 3,983 & $<.001$ \\
\hline GNV STATUS -> COMPRA & H7 & 0,306 & 0,302 & 0,040 & 7,669 & $<.001$ \\
\hline RENDA -> COMPRA & H8 & 0,190 & 0,192 & 0,038 & 5,015 & $<.001$ \\
\hline RENDA -> PROMOÇÃO & H9 & $-0,189$ & $-0,195$ & 0,036 & 5,174 & $<.001$ \\
\hline
\end{tabular}

Fonte: Elaborado pelo autor com dados advindos da coleta, usando os softwares SPSS v.22 e SmartPLS 2.0.

H2 é validada na medida em que o Grupo de Referência não se demonstra estatisticamente significativo em seu impacto ao volume de compra $(\beta=0,019)$. H3 é suportada, tendo em vista seu impacto positivo e direto na cocriação $(\beta=0,331)$. Quanto maior a importância dada ao grupo de referência, maior o engajamento $(\beta=0235)$, validando $\mathbf{H}_{4}$. H5 é suportada, tendo em vista que, quanto maior a importância à cocriação por parte do torcedor, 
Munaier, C. G. e S. (2021, set./dez.). "Manto da massa": pertencimento, cocriação e engajamento em uma campanha histórica de vendas de camisas oficiais no futebol brasileiro

maior seu engajamento $(\beta=0,240)$. Maior engajamento, maior volume de compra $(\beta=0,151)$, validando H6. O status de membro do programa de lealdade "Galo na Veia" impacta positivamente o volume de compra observado, validando $\mathbf{H}_{7}(\beta=0,307)$. Como hipotetizado, quanto maior a renda, maior o volume de compra, validando $\mathbf{H}_{8}(\beta=0,190)$, e menor o apreço à promoção, conforme se vê no beta negativo: $\beta=-0,189$. Esse resultado valida $\mathbf{H 9}$.

Para um melhor entendimento quanto à importância do engajamento na campanha para que fossem atingidas as 100.000 peças vendidas, procedeu-se uma ANOVA. Foi observado o número de estratégias (nenhuma, uma ou todas) utilizadas na ação do indivíduo de convencer o maior número possível de pessoas a também aderir à campanha. Com mais de 20 graus de liberdade ante uma análise de Shapiro-Wilk e distribuição homogênea dos dados, obteve-se F $(2,552)=7,379 ; \mathrm{p}=0,001$, demonstrando que há diferença estatisticamente significante entre a intensidade no engajamento do indivíduo e o volume de compras que ele fez.

\section{Tabela 5.}

Post-hoc Duncan para Volume de Compra e Engajamento

\begin{tabular}{llcc|c}
\hline \multicolumn{2}{c}{ VOLUME DE COMPRA } \\
\hline \hline & ENGAJAMENTO & $N$ & \multicolumn{2}{c}{ Subset for alpha $=0.05$} \\
Duncan $^{\mathrm{a}, \mathrm{b}}$ & & 1 & 2 \\
& Sem engajamento & 138 & 1,7391 & \\
& Com 1 ferramenta de engajamento & 276 & & 2,0109 \\
& Com todas as ferramentas de engajamento & 141 & & 2,1277 \\
Sig. & & 1,000 &, 223 \\
\hline
\end{tabular}

Fonte: Elaborado pelo autor com dados advindos da coleta, usando o software SPSS v. 22.

O teste post-hoc Duncan demonstra haver diferença entre quem não se engajou na campanha e quem se engajou. Não há diferença entre quem usou apenas uma ferramenta ou todas. A Tabela 5 apresenta os dados do post-hoc e a Figura 3 apresenta as médias de compras versus a intensidade de engajamento do comprador. 
Munaier, C. G. e S. (2021, set./dez.). "Manto da massa": pertencimento, cocriação e engajamento em uma campanha histórica de vendas de camisas oficiais no futebol brasileiro

\section{Figura 3.}

Gráfico das Médias do Volume de Compra por Grau de Engajamento.

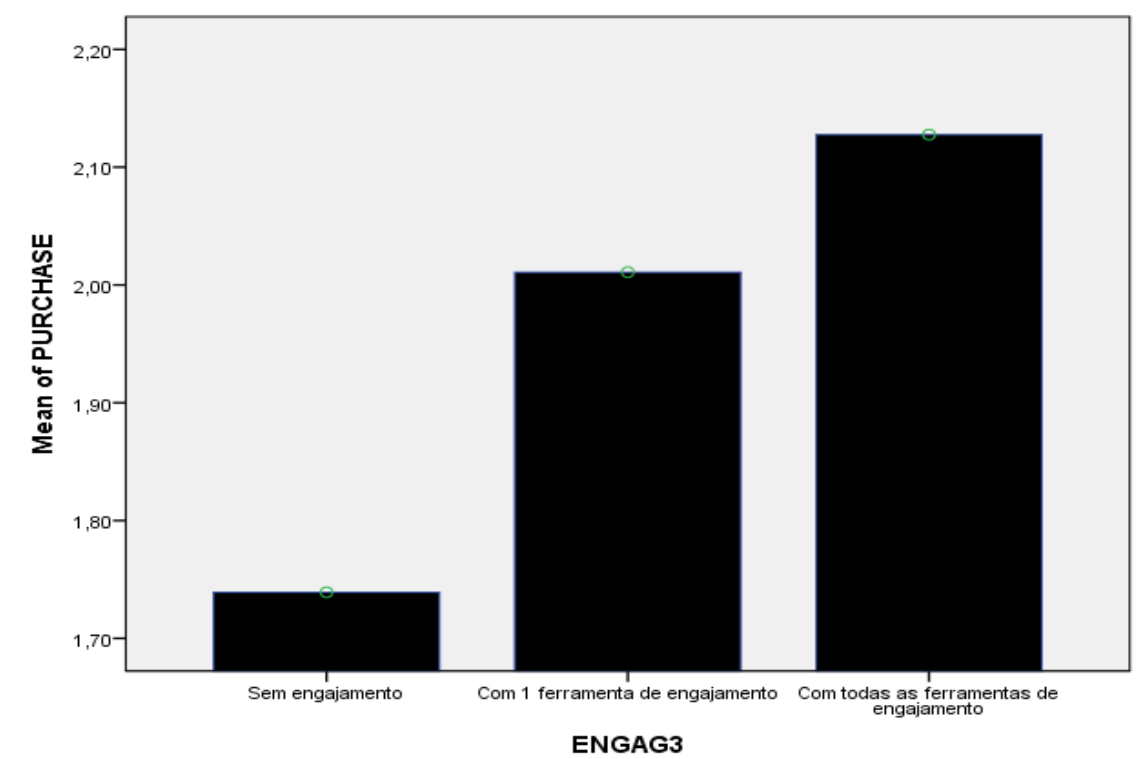

Fonte: Elaborado pelo autor com dados advindos da coleta, usando o software SPSS v. 22.

\section{Tabela 6.}

Post-hoc Duncan para Volume de Compra e Renda

\begin{tabular}{llcr|r}
\hline \multicolumn{2}{c}{ VOLUME DE COMPRA } \\
\hline \hline \multirow{2}{*}{ Runcan ${ }^{\mathrm{a}, \mathrm{b}}$} & $\mathbf{N}$ & \multicolumn{2}{c}{ Subset for alpha $=\mathbf{0 . 0 5}$} \\
& De 1 SM a menos de 2 SM & 82 & 1 & \multicolumn{2}{c}{2} \\
& Sem rendimento a 1/2 SM & 39 & 1,5976 & \\
De 2 SM a menos de 3 SM & 80 & 1,6154 & \\
De 3 SM a menos de 5 SM & 123 & 1,8750 & 1,8750 \\
Com 5 SM ou mais & 231 & & 2,0650 \\
Sig. & & & 2,1515 \\
& & &, 054 &, 055 \\
\hline
\end{tabular}

Fonte: Elaborado pelo autor com dados advindos da coleta, usando o software SPSS v. 22.

Conforme validado na Tabela 4 , renda impacta o volume de compra $\left(\mathrm{H}_{8}\right)$. Com mais de 20 graus de liberdade entre os grupos de faixa de renda, procedeu-se uma ANOVA com teste post-hoc Duncan para observar o impacto da renda no volume de compra. Com F $(4,550)=$ 8,649; $\mathrm{p}=0,000$, reafirma-se a importância da renda no número de camisas compradas pelo indivíduo. O teste post-hoc Duncan, conforme se observa na Tabela 6, demonstra que há diferença estatística entre o volume de compra de consumidores entre as faixas sem renda até menos de 2 salários-mínimos por mês, e os compradores com 3 ou mais salários-mínimos por mês. Os compradores com renda entre 2 a menos de 3 salários-mínimos não têm diferença 
Munaier, C. G. e S. (2021, set./dez.). "Manto da massa": pertencimento, cocriação e engajamento em uma campanha histórica de vendas de camisas oficiais no futebol brasileiro

estatisticamente significante nem com os primeiros e nem com os últimos. A Figura 4 traz uma representação gráfica dos grupos.

A renda também impacta a percepção de oportunidade que as promoções trazem $\left(\mathrm{H}_{9}\right)$. A ligação entre renda e o construto Apreço à Promoção, observada na Tabela 4, apresenta $\beta$ negativo $(-0,189)$, mostrando, ainda, que quanto maior a renda, menor o apreço à promoção. Com mais de 20 graus de liberdade entre os grupos de faixa de renda no teste de Shapiro-Wilk, procedeu-se uma ANOVA com teste post-hoc DMS para observar o impacto da renda no Apreço à Promoção. Com $\mathrm{F}(4,550)=6,820 ; \mathrm{p}=0,000$, reafirma-se a importância da renda no número de camisas compradas pelo indivíduo.

O teste post-hoc DMS demonstra que há diferença estatisticamente significante entre os compradores com renda igual ou superior a 5 salários-mínimos e as demais faixas de renda, conforme se observa na Tabela 7 e Figura 5.

\section{Figura 4.}

Gráfico das Médias do Volume de Comprapor

Renda

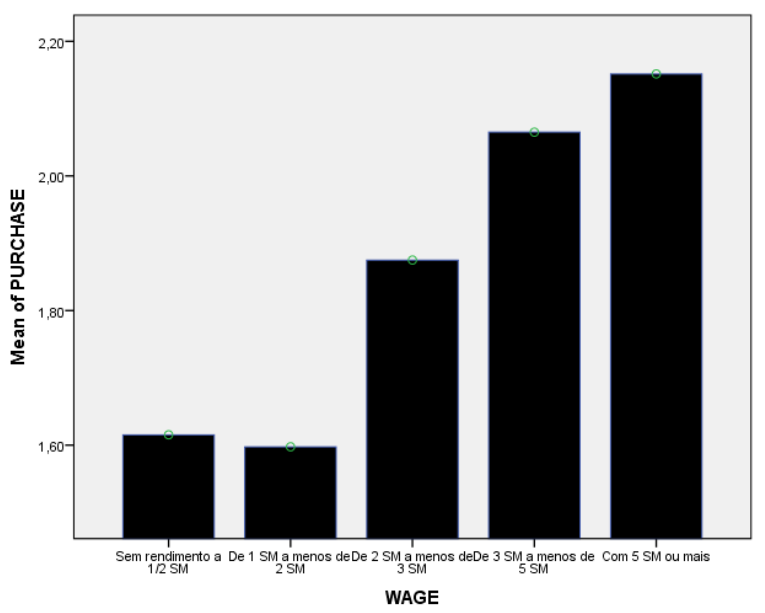

Fonte: Elaborado pelo autor com dados advindos da coleta, usando o software SPSS v. 22.

\section{Figura 5.}

Gráfico da Média de Apreço à Promoção por Renda

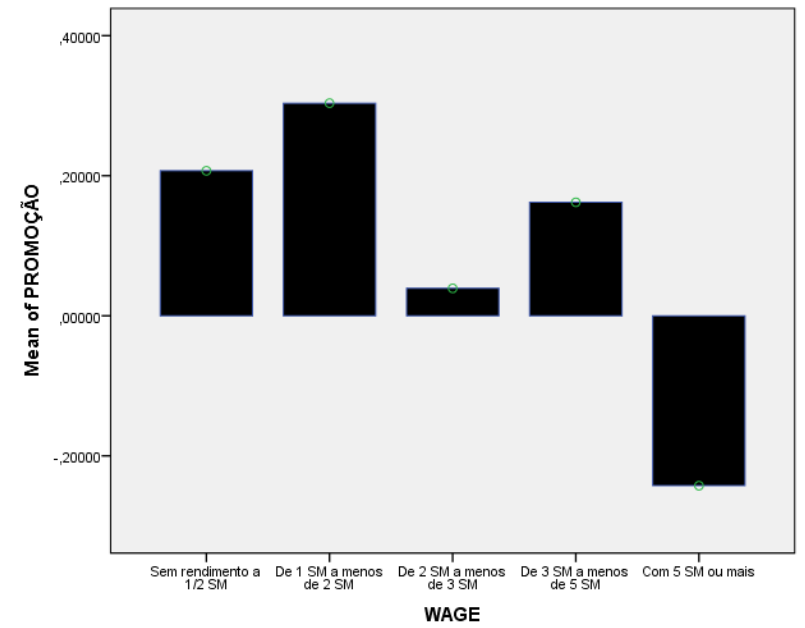

Fonte: Elaborado pelo autor com dados advindos da coleta, usando o software SPSS v. 22 
Munaier, C. G. e S. (2021, set./dez.). "Manto da massa": pertencimento, cocriação e engajamento em uma campanha histórica de vendas de camisas oficiais no futebol brasileiro

\section{Tabela 7.}

Post-hoc DMS para Apreço à Promoção e Renda

\begin{tabular}{|c|c|c|c|c|c|c|}
\hline \multirow[t]{2}{*}{ (I) RENDA } & \multirow[t]{2}{*}{ (J) RENDA } & \multirow{2}{*}{$\begin{array}{c}\text { Mean Difference } \\
\text { (I-J) }\end{array}$} & \multirow[t]{2}{*}{ Std. Error } & \multirow[t]{2}{*}{ Sig. } & \multicolumn{2}{|c|}{ 95\% Confidence Interval } \\
\hline & & & & & Lower Bound & Upper Bound \\
\hline \multicolumn{2}{|c|}{ Sem rendimento a $1 / 2$ De $1 \mathrm{SM}$ a menos de $2 \mathrm{SM}$} &,- 09654231 & , 19055301 & ,613 &,- 4708430 & ,2777584 \\
\hline \multirow[t]{3}{*}{ SM } & De $2 \mathrm{SM}$ a menos de $3 \mathrm{SM}$ &, 16784798 & , 19131919 &, 381 &,- 2079577 &, 5436537 \\
\hline & De $3 \mathrm{SM}$ a menos de $5 \mathrm{SM}$ & 04497189 &, 18002591 &, 803 &,- 3086506 & ,3985944 \\
\hline & Com 5 SM ou mais & ,44963986* & 16959223 &, 008 &, 1165121 & ,7827676 \\
\hline \multicolumn{2}{|c|}{ De $1 \mathrm{SM}$ a menos de $2 \mathrm{Sem}$ rendimento a $1 / 2 \mathrm{SM}$} & ,09654231 & , 19055301 & ,613 &,- 2777584 & ,4708430 \\
\hline \multirow[t]{3}{*}{ SM } & De $2 \mathrm{SM}$ a menos de $3 \mathrm{SM}$ & ,26439029 & , 15394584 & ,086 &,- 0380034 & ,5667840 \\
\hline & De $3 \mathrm{SM}$ a menos & 51420 &, 13966250 &, 311 &,- 1328230 & ,4158514 \\
\hline & Com 5 SM ou mais &, $54618217^{*}$ & 12592780 &, 000 & ,2988239 & ,7935405 \\
\hline \multicolumn{2}{|c|}{ De $2 \mathrm{SM}$ a menos de $3 \mathrm{Sem}$ rendimento a $1 / 2 \mathrm{SM}$} &,- 16784798 & ,19131919 & ,381 &,- 5436537 & ,2079577 \\
\hline \multirow[t]{3}{*}{ SM } & De $1 \mathrm{SM}$ a menos de $2 \mathrm{SM}$ &,- 26439029 & , 15394584 & ,086 &,- 5667840 & ,0380034 \\
\hline & De $3 \mathrm{SM}$ a menos de $5 \mathrm{SM}$ &,- 12287608 &, 14070607 &, 383 &,- 3992631 &, 1535110 \\
\hline & Com 5 SM ou mais & ,28179189* &, 12708420 &, 027 & 0321621 &, 5314217 \\
\hline \multicolumn{2}{|c|}{ De $3 \mathrm{SM}$ a menos de $5 \mathrm{Sem}$ rendimento a $1 / 2 \mathrm{SM}$} &,- 04497189 & , 18002591 & ,803 &,- 3985944 & ,3086506 \\
\hline \multirow[t]{3}{*}{ SM } & De $1 \mathrm{SM}$ a menos de $2 \mathrm{SM}$ &,- 14151420 &, 13966250 &, 311 &,- 4158514 & ,1328230 \\
\hline & De $2 \mathrm{SM}$ a menos de $3 \mathrm{SM}$ & , 12287608 & , 14070607 &, 383 &,- 1535110 & ,3992631 \\
\hline & Com 5 SM ou mais & ,40466797* & , 10934664 &, 000 & , 1898798 & ,6194561 \\
\hline \multirow[t]{4}{*}{ Com 5 SM ou mais } & Sem rendimento a $1 / 2 \mathrm{SM}$ &,$- 44963986^{*}$ & , 16959223 & ,008 &,- 7827676 &,- 1165121 \\
\hline & De $1 \mathrm{SM}$ a menos de $2 \mathrm{SM}$ &,$- 54618217^{*}$ & , 12592780 &, 000 &,- 7935405 &,- 2988239 \\
\hline & De $2 \mathrm{SM}$ a menos de $3 \mathrm{SM}$ &,$- 28179189^{*}$ & , 12708420 &, 027 &,- 5314217 &,- 0321621 \\
\hline & De $3 \mathrm{SM}$ a menos de $5 \mathrm{SM}$ &,$- 40466797^{*}$ & , 10934664 &, 000 &,- 6194561 &,- 1898798 \\
\hline
\end{tabular}

Fonte: Elaborado pelo autor com dados advindos da coleta, usando o software SPSS v. 22.

\section{Conclusões, sugestões e limitações}

Kolyperas et al. (2019), em seu trabalho qualitativo, buscaram responder qual o papel do consumidor na cocriação de valor. Este trabalho buscou contribuir quantitativamente à seguinte pergunta: qual o papel do engajamento, do sentimento de pertencimento ao grupo, da cocriação de valor e da renda no resultado de uma campanha histórica de vendas de camisas oficiais de um clube de futebol?

Neste sentido, a primeira contribuição do manuscrito é no sentido de trazer novos elementos para a literatura do comportamento do consumidor e cultura do consumo no mercado esportivo, lacuna identificada por Hewer et al. (2017) e Kolyperas et al. (2019). A importância dada pelo indivíduo aos signos de pertencimento trazidos pelo uniforme de um clube apresentase semelhante onde quer que o comprador resida. Esse sentimento de identificação, de credenciamento à 'tribo' através da sua posse e uso do uniforme de futebol, ultrapassa os limites geográficos de onde atua com mais intensidade a equipe em questão. Essas descobertas estão 
Munaier, C. G. e S. (2021, set./dez.). "Manto da massa": pertencimento, cocriação e engajamento em uma campanha histórica de vendas de camisas oficiais no futebol brasileiro

em consonância e fazem avançar a literatura pregressa (Hewer et al., 2017; Tsiotsou, 2016; Wan et al., 2014).

Outra contribuição para a literatura é avançar no entendimento das motivações sociais no engajamento e geração do eWOM, sob a lente teórica da Lógica S-D. Coadunando ao ecossistema de serviços para o marketing esportivo baseado nas experiências (Tsiotsou, 2016), este artigo demonstra que a seguinte sequência se sustenta: sensação de pertencimento ao grupo de referência $\rightarrow$ importância dada à cocriação de experiências $\rightarrow$ engajamento do consumidor no eWOW $\rightarrow$ volume de compra. Observou-se que, quanto maior a sensação de pertencimento por parte do indivíduo, maior o seu engajamento e o seu desejo de participar dos processos de cocriação com o fornecedor de material esportivo.

Outra contribuição deste artigo é sustentar que o engajamento do indivíduo via cocriação é maior do que o seu engajamento apenas pela sensação de pertencimento. Esses resultados estão em consonância com outras pesquisas sobre engajamento e lealdade do consumidor em comunidades virtuais (Brodie et al., 2013; Kandampully et al., 2015), aqui observado no consumo esportivo. Ou seja: ao menos em ações comerciais no esporte, não basta pertencer; para maior engajamento, é fundamental participar (Kolyperas et al., 2019; Tsiotsou, 2016). Essas descobertas apoiam e incrementam o entendimento de que a motivação pró-social leva à participação do consumidor, proporcionando um compromisso com a marca, resultando no eWOM (An et al., 2019).

Em conformidade com a literatura sobre consumos e rendas, este artigo traz para a literatura na cultura de consumos no esporte uma análise quanto à renda (Kamakura \& Mazzon, 2016) e ao apelo a promoções (Lamberton \& Stephen, 2016). Identificou-se que, quanto maior a renda, maior o volume de camisas compradas. E quanto ao impacto do valor promocional, ressalta-se ter sido observado que o apreço à promoção tem diferença estatística em relação à renda: quanto maior a renda, menor a média do apreço à promoção, sendo essa outra contribuição para a literatura entre os achados deste artigo.

Nesta pesquisa, a linha de corte foram 5 salários-mínimos ou mais como sendo a faixa de renda que tem menor apreço à promoção em detrimento das faixas de renda menores. Essa contribuição é tanto para a literatura quanto para as práticas gerenciais, avançando na observação empírica o que já preconizavam Kamakura e Mazzon (2016): a riqueza da família é condição que define sua capacidade de consumo, e que acima de $30 \%$ do consumo não essencial está concentrado no segmento mais abastado (8,4\% dos domicílios brasileiros). 
Munaier, C. G. e S. (2021, set./dez.). "Manto da massa": pertencimento, cocriação e engajamento em uma campanha histórica de vendas de camisas oficiais no futebol brasileiro

Portanto, é possível propor que maior renda $\rightarrow$ maior o percentual de compras não essenciais $\rightarrow$ menor a atenção dada às promoções para a aquisição de consumos não essenciais.

\subsection{Implicações gerenciais}

Este artigo traz importantes insights gerenciais para os operadores do marketing dos clubes de futebol. O primeiro deles está atrelado à questão da territorialidade. No caso em análise, para o Atlético-MG, é possível sustentar que os esforços de vendas podem ultrapassar as barreiras geográficas, não restringindo suas ações apenas à Região Metropolitana de Belo Horizonte ou aos limites de Minas Gerais. Tanto para as estratégias de suas lojas próprias e exclusivas de material esportivo quanto para fornecedores, há razões para se identificar, para além do seu estado, onde se concentram volumes maiores de seus torcedores e ali desenvolver estratégias de comunicação pautadas no "pertencer", "ser", além das memórias e ancestralidades. Os consumidores de clubes de futebol querem ser parte e, em sendo (e não negligenciados), irão consumir (Hewer et al., 2017; Munaier \& Las Casas, 2019).

O engajamento nas mídias sociais parece ser o ponto de conexão entre o pertencimento e o volume histórico de venda do Clube Atlético Mineiro, apresentando-se como variável mediadora entre o pertencimento e o volume de compra feito pelo comprador, importante contribuição teórica e gerencial do presente manuscrito. Logo, em estratégias mais bem construídas, não basta estimular o pertencimento. Há que estimular o consumidor também a participar do processo de coprodução. É possível concluir que, dessa forma, o engajamento será maior. E quanto maior o engajamento, maior o volume de compra por parte do consumidor.

O engajamento nas mídias sociais, identificado como necessário para a produção de conteúdos gerados por usuários, para o boca a boca e para a decisão de compra (Goldenberg et al., 2012; Lamberton \& Stephen, 2016; Standing et al., 2016; Zhang et al., 2011) assume, dentre as conclusões deste artigo, importante papel na decisão do volume de compra. É possível concluir que, quando há o engajamento na divulgação feita pelo comprador para que outros também consumam, estimulando seus pares com a publicização da sua própria decisão de consumo, maior o seu próprio volume de compra. Reside, neste achado, uma contribuição do presente artigo tanto para a literatura quanto para as estratégias gerenciais. Estimular e monitorar o engajamento dos consumidores nas mídias sociais podem permitir não apenas estimular a decisão de compra, mas o volume dela. 
Munaier, C. G. e S. (2021, set./dez.). "Manto da massa": pertencimento, cocriação e engajamento em uma campanha histórica de vendas de camisas oficiais no futebol brasileiro

São, de início, três os grandes desafios na gestão de promoções como a proposta pelo Clube Atlético Mineiro: 1) Identificar o que une os consumidores em prol de uma marca para estimular o sentimento de pertencimento; 2) Oferecer o espaço dialógico para que os consumidores participem do seu processo criativo e decisório; 3) Desenvolver estratégias de engajamento em prol de uma causa e uma meta para ser atingida. Conforme sustentam Huertas et al. (2012), a internet pode ser esse ambiente facilitador desse processo. Quando baseado nas experiências do consumidor em sua cocriação de valor, esse é o ecossistema de serviços do século 21 (Kolyperas et al., 2019; Prahalad \& Ramaswamy, 2000; Tsiotsou, 2016).

O volume de compras por pessoa é também explicado pela condição de inscrito ou não ao programa sócio torcedor Galo na Veia. É possível inferir que compradores tenham usado do seu status de participante do GNV para adquirir camisas a preço promocional para não participantes. Como essa condição não foi mensurada, reside aí uma das limitações do presente artigo e sugestão para pesquisas vindouras, tratando essas possíveis “compras solidárias" como covariável a ser observada.

\subsection{Sugestões e limitações}

À luz da Lógica S-D, o universo de possibilidades nas ações dos clubes esportivos e suas estratégias de branding são muitas. Por exemplo, buscar avaliar o grau de engajamento do fandom em campanhas de cocriação patrocinadas por marcas controversas ou alinhadas politicamente a um determinado posicionamento ideológico pode trazer novos olhares sobre este fenômeno no futebol. Outra sugestão, recomenda-se analisar essas mesmas hipóteses em outras campanhas de clubes brasileiros e/ou internacionais, bem como em outros esportes.

Outra possiblidade de avanço a partir deste manuscrito é testar o grau de satisfação quanto à qualidade do produto, uma vez produzido e entregue. Será que o mock-up feito pelo(a) torcedor(a) tem a mesma qualidade do design da fornecedora esportiva? Ainda, pode-se verificar se as outras formas de cocriação de valor nos ecossistemas baseados em experiências do fã de esportes, tais como os "Fan tokens" (ativos digitais comercializados pelos clubes), despertam o mesmo engajamento que produtos físicos (como uniformes oficiais).

Dentre as limitações, a primeira se concentra no método usado. Foi utilizada a Modelagem de Equações Estruturais para medir os caminhos. Uma alternativa poderia ser as regressões diretas e a utilização do modelo 4 (mediação) do Process para medir o caminho direto entre cocriação de valor e volume de compra, e o caminho indireto entre essas duas 
Munaier, C. G. e S. (2021, set./dez.). "Manto da massa": pertencimento, cocriação e engajamento em uma campanha histórica de vendas de camisas oficiais no futebol brasileiro

variáveis passando pelo engajamento. Essa também é uma recomendação para pesquisa futura. Outra limitação é o tamanho da coleta. Ainda que 555 seja um n expressivo, não é possível generalizar seus achados. Logo, identificar o tamanho da amostra probabilística e executar uma nova pesquisa com a mesma escala pode ser uma nova sugestão. Não testar outras covariáveis, como as compras solidárias feitas pelos membros do programa de lealdade para os não membros, é outra limitação. E o número extenso de hipóteses pode ser uma limitação deste artigo.

\section{Referências}

An, J., Ngo, L. V., Chylinski, M., \& Tran, Q. (2019). Customer advocates with a generous heart. Journal of Services Marketing, 33(2), 192-205. https://doi.org/10.1108/JSM-04-20180120

Belk, R. W. (2013). Extended self in a digital world. Journal of Consumer Research, 40(3), 477-500. https://doi.org/10.1086/671052

Brodie, R. J., Ilic, A., Juric, B., \& Hollebeek, L. (2013). Consumer engagement in a virtual brand community: An exploratory analysis. Journal of Business Research, 66(1), 105-114. https://doi.org/10.1016/j.jbusres.2011.07.029

CAM. (2020). Manto da Massa. Manto Da Massa 2020. www.mantodamassa.com.br

Creswell, J. W. (2007). Projeto de pesquisa: métodos qualitativo, quantitativo e misto. In Journal of Chemical Information and Modeling (2nd ed., Vol. 2). Artmed.

Fornell, C., \& Larcker, D. F. (1981). Evaluating Structural Equation Models with Unobservable Variables and Measurement Error. Journal of Marketing Research, 18(1), 39. https://doi.org/10.2307/3151312

Freyre, G. (1996). Manifesto regionalista. In FUNDAJ (7ª). Ed. Massangana.

GE. (2020a, June 5). Uniformes criados por torcedores ganham espaço em times; veja novos e antigos modelos. GloboEsporte.Com. https://ge.globo.com/pe/futebol/noticia/uniformescriados-por-torcedores-ganham-espaco-em-times-veja-novos-e-antigos-modelos.ghtml

GE. (2020b, September 11). Atlético-MG exibe "Manto da Massa" pronto e celebra sucesso: "A história está sendo escrita." GloboEsporte.Com. https://ge.globo.com/futebol/times/atletico-mg/noticia/atletico-mg-exibe-manto-da-massapronto-e-celebra-sucesso-a-historia-esta-sendo-escrita.ghtml

Goldenberg, J., Oestreicher-Singer, G. A. L., \& Reichman, S. (2012). The quest for content: How user-generated links can facilitate online exploration. Journal of Marketing Research, 49(4), 452-468. https://doi.org/10.1509/jmr.11.0091 
Munaier, C. G. e S. (2021, set./dez.). "Manto da massa": pertencimento, cocriação e engajamento em uma campanha histórica de vendas de camisas oficiais no futebol brasileiro

Hair, Jr., J. F. H., Black, W. C., Babin, B. J., Anderson, R. E., \& Tatham, R. L. (2009). Análise Multivariada de Dados (6 ed). Artmed.

Hair, J. F., Harrison, D. E., \& Risher, J. J. (2018). Marketing research in the 21st century: Opportunities and challenges. In Revista Brasileira de Marketing (Vol. 17, Issue 5). https://doi.org/10.5585/bjm.v17i5.4173

Helkkula, A., Kelleher, C., \& Pihlström, M. (2012). Characterizing Value as an Experience: Implications for Service Researchers and Managers. Journal of Service Research, 15(1), 5975. https://doi.org/10.1177/1094670511426897

Hewer, P., Gannon, M., \& Cordina, R. (2017). Discordant fandom and global football brands: "Let the people sing." Journal of Consumer Culture, 17(3), 600-619.

https://doi.org/10.1177/1469540515611199

Huang, S. L., \& Chen, C. T. (2018). How consumers become loyal fans on Facebook. Computers in Human Behavior, 82, 124-135. https://doi.org/10.1016/j.chb.2018.01.006

Huertas, M. K. Z., Varela, C. A., \& Strehlau, S. (2012). Co-Criação Na Internet: Uma Análise Das Perspectivas Da Empresa E Do Consumidor. Review of Administration and Innovation RAI, 9(3). https://doi.org/10.5773/rai.v9i3.956

Hughes, T., \& Vafeas, M. (2018). Service-dominant logic as a framework for exploring research utilization. Marketing Theory, 18(4), 451-472.

https://doi.org/10.1177/1470593118764019

Ikeda, A. A., \& Veludo-de-Oliveira, T. M. (2005). O conceito de valor para o cliente: definições e implicações gerenciais em marketing. REAd. Revista Eletrônica de Administração, 11(2), 1-22. https://doi.org/10.4324/9780080464862-9

Kamakura, W., \& Mazzon, J. A. (2016). Critérios de estratificação e comparação de classificadores socioeconômicos no Brasil. Revista de Administração de Empresas, 56(1), 5570. https://doi.org/10.1590/s0034-759020160106

Kandampully, J., Zhang, T. (Christina), \& Bilgihan, A. (2015). Customer loyalty: A review and future directions with a special focus on the hospitality industry. International Journal of Contemporary Hospitality Management, 27(3), 379-414. https://doi.org/10.1108/IJCHM-032014-0151

Kolyperas, D., Maglaras, G., \& Sparks, L. (2019). Sport fans' roles in value co-creation. European Sport Management Quarterly, 19(2), 201-220. https://doi.org/10.1080/16184742.2018.1505925

Lamberton, C., \& Stephen, A. T. (2016). A thematic exploration of digital, social media, and mobile marketing: Research evolution from 2000 to 2015 and an agenda for future inquiry. Journal of Marketing, 80(6), 146-172. https://doi.org/10.1509/jm.15.0415

Lichtenstein, D. R., Ridgway, N. M., \& Netemeyer, R. G. (1993). Price Perceptions and 
Munaier, C. G. e S. (2021, set./dez.). "Manto da massa": pertencimento, cocriação e engajamento em uma campanha histórica de vendas de camisas oficiais no futebol brasileiro

Consumer Shopping Behavior: A Field Study. Journal of Marketing Research, 30(2), 234. https://doi.org/10.2307/3172830

Lusch, R. F., \& Vargo, S. L. (2006). Service-dominant logic: Reactions, reflections and refinements. Marketing Theory, 6(3), 281-288. https://doi.org/10.1177/1470593106066781

Lusch, R. F., Vargo, S. L., \& O’Brien, M. (2007). Competing through service: Insights from service-dominant logic. Journal of Retailing, 83(1), 5-18.

https://doi.org/10.1016/j.jretai.2006.10.002

Maslow, A. H. (1970). Motivation and personality. Harper \& Row.

Munaier, C. G. e S., \& da Costa, C. R. M. (2021). Influence of usage and contractual binds on customer retention in Continually Delivered Services: evidence from the Physical Fitness Business. RISUS - Journal on Innovation and Sustainability, 12, 101-114.

https://doi.org/10.23925/2179-3565.2021v12i2p101-114

Munaier, C. G. e S., \& Las Casas, A. L. (2019). A Membership Program and a Complain Website: How Sport Clubs Manage Experiences of Their Members. Journal on Innovation and Sustainability RISUS, 10(3), 75-87. https://doi.org/10.23925/2179-3565.2019v10i3p7587

Munaier, C. G. e S., Rocha, R. R., \& Portes, J. H. (2020). A confiança em marcas de serviços: quando a sede física da empresa potencializa sua relação com o consumidor. XXIII SemeAd, $1-15$.

Nalbantis, G., Fahrner, M., \& Pawlowski, T. (2017). The demand for licensed merchandise in sports-on the purchase channel choice. Journal of Sport Management, 31(5), 433-451. https://doi.org/10.1123/jsm.2016-0179

Nambisan, S., \& Nambisan, P. (2008). How to Profit from a Better Virtual Customer Environment'. MIT Sloan Management Review, 49(3), 53-61.

Park, C. W., \& Lessig, V. P. (1977). Students and Housewives: Differences in Susceptibility to Reference Group Influence. Journal of Consumer Research, 4(2), 102.

https://doi.org/10.1086/208685

Prahalad, C. K. ;, \& Ramaswamy. (2000). Co-opting Customer Competence. Harvard Business Review, 78(2), 79-87.

Rosendahl, Z. (2005). Território E Territorialidade : Uma Perspectiva. Anais Do X Encontro de Geógrafos Da América Latina, 12928-12942.

Standing, C., Holzweber, M., \& Mattsson, J. (2016). Exploring emotional expressions in eword-of-mouth from online communities. In Information Processing and Management (Vol. 52, Issue 5, pp. 721-732). https://doi.org/10.1016/j.ipm.2016.01.001

Strizhakova, Y., Coulter, R. A., \& Price, L. L. (2008). The meanings of branded products: A cross-national scale development and meaning assessment. International Journal of Research 
Munaier, C. G. e S. (2021, set./dez.). "Manto da massa": pertencimento, cocriação e engajamento em uma campanha histórica de vendas de camisas oficiais no futebol brasileiro

in Marketing, 25(2), 82-93. https://doi.org/10.1016/j.ijresmar.2008.01.001

Trusov, M., Bucklin, R. E., \& Pauwels, K. (2009). Effects of word-of-mouth versus traditional marketing: Findings from an internet social networking site. Journal of Marketing, 73(5), 90-102. https://doi.org/10.1509/jmkg.73.5.90

Tsiotsou, R. H. (2016). A service ecosystem experience-based framework for sport marketing. Service Industries Journal, 36(11-12), 478-509. https://doi.org/10.1080/02642069.2016.1255731

Vargo, S. L., \& Lusch, R. F. (2008). Service-dominant logic: Continuing the evolution. Journal of the Academy of Marketing Science, 36(1), 1-10. https://doi.org/10.1007/s 11747007-0069-6

Wan, E. W., Xu, J., \& Ding, Y. (2014). To be or not to be unique? the effect of social exclusion on consumer choice. Journal of Consumer Research, 40(6), 1109-1122. https://doi.org/10.1086/674197

Zhang, M., Jansen, B. J., \& Chowdhury, A. (2011). Business engagement on Twitter: A path analysis. Electronic Markets, 21(3), 161-175. https://doi.org/10.1007/s12525-011-0065-Z

Zhang, Y., Trusov, M., Stephen, A. T., \& Jamal, Z. (2017). Online shopping and social media: Friends or foes? Journal of Marketing, 81(6), 24-41.

https://doi.org/10.1509/jm.14.0344 